\title{
COLOR PATTERNS IN BLASTOIDS
}

*BEAVER, Harold H., Department of Geology, Waco, Texas 76798, U.S.A.;

FABIAN, Alexander J., 27016 Jackman Rd., Temperance, Michigan 48182, U.S.A.

Approximately 50 specimens of Pentremites collected from the Upper Mississippian of the Mid-Continent Region of the United States exhibit color paterns; these color patterns can be subdivided into three different types.

Type one color pattern is characterized by horizontal bands of darker calcite occurring on the main body of the radials. These darker bands, numbering ten or more in vertical succession, cross from one radial to the adjoining radial. The bands terminate against the ambulacra. Tiny raised areas are spaced along the bands. On the deltoids, the darker bands, ranging from several to six or more, occur as arched, convex chevrons.

Type two color pattern differs from Type One in that the patterns on the deltoidal areas are confined to a band on the radial-deltoid suture and as an immediately lower band. Both bands are concave. A vertical band coincides with the radial sutures. Darker calcite also occurs on the lower portions of each ambulacrum and on the mid-basal regions.

Type Three color pattern has alternating concave bands of light and dark calcite on the deltoids. Three or four alternating bands may be present. A vertical band coincides with the suture of adjoining radials and also on the sutures of the basals.. This type differs from Types One and Two in that the radial bodies have many transverse dark streaks of calcite, most of which are very thin and curving, and are nearly perpendicular to the growth lines of the radials.

This color pattern is similar to Type Two in that broad areas of darker calcite occur in broad bands surrounding the lower portions of each ambulacrum and are present in the mid-basal regions.

Only two previous occurrences of original color patterns or markings in blastoids have been published (Reimann, Irving G., 1961, A Color-marked Devonian Blastoid. Oklahoma Geology Notes: 21 (5): 153-157, Sprinkle, James, 1973, Morphology and Evolution of Blastozoan Echinoderms, Special Publication, The Museum Comparative Zoology, Harvard University, Cambridge). In both cases, the color patterns described formed bands of tiny growth lines paralleling plate growth lines. 